\title{
Research on the Application of Computer "Virtual Reality" Technology in Physical Education of Colleges and Universities
}

\author{
Yaoliang Zhang \\ Zhuhai College of Jilin University \\ cpcimeici2018@163.com
}

\begin{abstract}
Keywords: Computer "virtual reality" technology; Physical education of colleges and universities; The application strategy
\end{abstract}

\begin{abstract}
With the development of science and technology, computer has entered all walks of life and has obvious influence and role. The physical education has been the short board of the teaching in colleges and universities. With the education reform, advanced ideas are put forward and "virtual reality" technology of computer has been introduced to the physical education in middle school, which can greatly improve the effect and teaching level of physical education in colleges and universities and optimize the traditional physical education methods. It is one of the essential teaching means under the new era.

Computer technology has been deeply applied in all walks of life and has obtained very obvious advantages. Through reform, "virtual reality" technology has been brought into the classroom. Computer "virtual reality" technology enters the physical education of colleges and universities, which achieves the results that the traditional physical education mode cannot reach with high efficient. The application of computer "virtual reality" technology in physical education class is going to be one of the most important roles in physical education teaching reform in the future.
\end{abstract}

\section{Definition of Computer "Virtual Reality" Technology}

VR is the short form of "Virtual Reality". This kind of computer technology was first noticed by people in 1980s, which is 3D information artificial simulation environment that is composted by computer software, hardware and all kinds of sensing device. The technology has four main characteristics, such as multi-perceptual, interaction, idea and immersion. VR is to completely apply the four characteristics in physical education in colleges and universities, to vividly present the physical education action skills and the realistic scene and to make students be personally on the scene. VR technology does not only effectively arouse the enthusiasm of the students' physical education curriculum, but also greatly improves the quality of training, which makes modern sports can get great development and progress.

\section{The Characteristics of VR Technology}

With the progress of science and technology, education career also got rapid development. The improvement of comprehensive physical quality decides the healthy development of the whole society. Physical education of colleges and universities has gradually become the important subject to improve students' comprehensive quality. Being different from other subjects, physical education teaching emphasizes to master the practical operability and movement normalization, therefore, the real interactive teaching is critical. Due to the limitations of condition and space, as well as the problem of money, it is difficult to realize the effective teaching of efficient sports. The emergence of VR technology successfully achieves the comparison of virtual and reality on teaching. VR technology is not subject to regional restrictions, realizes long distance interactive teaching, fully mobilizes the enthusiasm of students, makes every student participate actively and give full play to their own subjective motivation. As a result, the application of VR technology in physical education teaching is of positive significance to the healthy sustainable development of the physical education teaching. The following content will detailed analyze the advantages of VR technology. 


\section{Characteristic of multi-perceptual}

Multi-perceptual refers to that since VR technology is made up of computer software, hardware, sensors and other components, so VR technology has the abilities to collect and analyze images. In addition, the virtual reality technology can also judge and analyze force field, magnetic field and other natural conditions and express by means of images. Vision is an important way to obtain external information, "virtual reality" technology has advanced stereo display technology, which provides a visual impact for people. At the same time, "virtual reality" technology has a 3D virtual voice reality technology in the composition and spread of the voice and provides people with the true stereo feeling, which enhances interactivity. The comprehensive effect of perception makes the virtual reality technology have specific information acquisition function, which is multi-perceptual characteristics of the virtual reality technology.

\section{Characteristic of interaction}

Computer "virtual reality" technology has significant characteristic in perceptual. The integration of virtual reality hardware devices and software technology and computer technology makes it have very strong sense of reality and give real stereo feeling in many senses for people. At the same time, the computer "virtual reality" technology has significant advantage in interaction. In the process of physical education, teachers can use computer "virtual reality" technology to make up for the defect of reality, or use the technology to realize the scene which does not exist to make integration of reality and imagination, which eventually meets the real needs and achieves the final satisfaction.

\section{Characteristic of idea}

The characteristic of idea is the same as the characteristic of interactivity in some sense. Both of the two characteristics are to simulate the scenes which do not exist in the reality by computer virtual reality technology. The characteristics of idea are mainly to broaden people's horizons and to develop people's imagination, which is to make some virtual scenes appear in front of people. So, the computer virtual reality technology can construct scene which does not exist in reality by artificial imagination.

\section{Characteristic of immersion}

The characteristic of immersion is a very important core technology in computer virtual reality technology. Because of the characteristic of immersion of virtual reality technology, the computer virtual reality technology cannot only simulate the scene, but also can make people have communication with virtual scene, which makes users have the immersive feelings and can have the same effect of the actual scene.

\section{Characteristic of the combination of computer and virtual reality technology}

Virtual reality technology has the characteristics of multi-perceptual and interactive, in addition, the advantage of computer cannot be forgotten. Because of a variety of reasons, the scene needs cannot be met in real life, VR technology can be selected according to the demands of people, which satisfies the communication willing of people and makes people feel like in the real scene, adds the fun of learning and arouses the enthusiasm of students. In addition to the advantages of virtual reality technology, the advantage of computer also adds scientific and convenience to physical education of colleges and universities. The statistical function and book analysis function of computers are one of the reasons that computer virtual technology has been widely recognized.

\section{The Problems Faced the Current Physical Education of Colleges and Universities}

With the vigorous development of the education cause and the introduction of new curriculum reform, China's education pays much attention to the development of students' comprehensive quality. Physical education is an important subject to improve students' physical quality. To strengthen the physical education of colleges and universities has far-reaching significance to promote the development of social stability and to improve the quality of people. However, traditional physical education has many shortcomings in the teaching methods and teaching modes, which is difficult to realize the scientific validity of physical education, weakens the interests on sports of students and greatly reduces the efficiency of physical education. The following will detailed analyze the defects existing in current physical education in colleges and universities. 


\section{The teaching method is single}

Being different from other subjects, physical education has high requests on action normalization and the practice ability of students. As a result, physical education should not only be limited to the classroom teaching, the combination of theory and practice is also particularly important. However, in the current physical education, paying attention to cultivate students' comprehensive quality which is the important content of the new curriculum reform is not well carried out. Some old teachers of physical education have no innovation in teaching models. The single teaching methods and boring teaching models are very difficult to stimulate students' interests in learning. it is difficult to play student's own subjective motivation under the conformity teaching model. Therefore, in the current physical education of colleges and universities, the teachers' single teaching method is also an important cause for the decline of the current teaching efficiency.

\section{Teachers as the main body of classroom}

The specification of sports actions in physical education is particularly important, which is not just a theoretical knowledge of textbooks, the interaction between teachers and students is important. Through training, teachers can effectively grasp students' learning status and degree of understanding. In the interactive training, at the same time, teachers and students also can have a closer relationship, which increases the emotion between teachers and students. At this stage, however, in physical education of colleges and universities, teacher is still the main body of the classroom, while students are in the passive state in learning. The new relationship between teachers and students cannot be set up. In physical education, students are completely under the thinking models of teachers and each step depends on teachers, which leaves no thinking space for students. The old teaching model is not conducive for students to explore the cultivation and weakens the students' innovation consciousness. Therefore, the teaching model that teacher as the main body and the classroom be lack of interaction is one of the problems facing physical education of colleges and universities.

\section{Unreasonable time arrangement of Physical Education}

Under the background of the traditional teaching, teacher spends a lot of energy on the three major courses, while considers Physical Education and Music to be less important. The teaching time is mainly arranged for the major courses. The courses, such as Chinese or Math even take up the time of Physical Education. The teaching time for Physical Education is less and teachers do not pay enough attention to Physical Education. As a result, students are different to pay enough attention. The traditional teaching methods and training ways do not only reduce the enthusiasm of students in physical education, at the same time, the traditional single physical education is difficult to guarantee the teaching quality. Poor quality, being lack of innovation teaching models and the unreasonable time arrangement of Physical Education are all the key elements to reduce the teaching efficiency of physical education of colleges and universities.

\section{The Application Strategies of Computer "Virtual Reality" Technology in Physical Education of Colleges and Universities}

With the progress of science and technology level, all kinds of advanced science and software application in teaching also increase. Computer network has the characteristics of wide spread, fast transmission speed and strong interaction. Computer "virtual reality" technology does not only incorporate the advantages of computer, but also adds virtual reality hardware devices and software technology, which makes it have strong simulation function and gain immersive feel from the senses. Physical education of colleges and universities should not only attach importance to the athletes' physical qualities, volleyball skills and tactics urgent, physical education emphasizes on practice. Only in practice can the normalization of actions be experienced. "Virtual reality" technology makes up the defect of the reality and arouses the enthusiasm of students. The application of computer "virtual reality" technology in physical education of colleges and universities shall be started from the characteristics of virtual technology and integrate the important points of physical education of colleges and universities. The following content will analyze the problems existing in the current physical education of colleges and universities in 
details. Combining with the characteristics of computer "virtual reality" technology, the implementation strategies of computer "virtual reality" technology in physical education of colleges and universities are given.

\section{Compare virtual and reality to optimize students' sports techniques}

Physical education has requests in normalization of actions, psychology of sports training, as well as the field adaptability. To combine practice with theory can achieve the unity and practice of physical education. With the improvement of computer technology, the simulation system can design scenes and actions according to the willing of designers. Teachers can compare virtual actions with late actions in physical education to make students find out their own shortcomings in order to correct actions and to make physical education be more standardized.

\section{Use virtual reality technology to build the super real training scene}

Computer virtual reality technology can simulate the scene which is infinitely close to the real scene, which can build the real training scene. In the virtual environment, athletes can have immersive feeling. The changes of training scenes in the virtual environment can stimulate the reflex of the movement of athletes. In addition, virtual scene can infinitely change into training scenes, which will not produce the training vision in the same scene and feeling fatigue for athletes, which is also one of the reasons that increase the training effects.

\section{Conclusion}

Computer technology has fully accessed to the education in colleges and universities. The computer virtual reality technology opens up a new field for the physical education of colleges and universities of our country. Although computer virtual reality technology has not been fully applied in physical education of colleges and universities in our country and there are also some problems of the technology, the computer virtual reality technology will be perfectly introduced to physical education of colleges and universities to improve the cause of physical quality training in young adults of our country through continuous development and discovery of the broad masses of workers. Therefore, only advancing with the times and introducing advanced equipment and training ideas, can the effect of physical education of colleges and universities be fundamentally improved.

\section{Reference}

[1] Liu Guiwen. Exploration of the Teaching Models of Physical Education Based on Virtual Reality Technology [J]. Electronic Testing, 2014, (18):63-65.

[2] Du Jianping. Application Analysis of Computer Virtual Technology in the Modern Physical Education[J]. Electronic Testing, 2014, (13):122-123.

[3] Chen Xue. Thinking of Building Group Cooperative Learning in line Teaching of Fine Arts in Elementary School[J]. New Curriculum (Elementary School), 2014, (04):96.

[4] Sun Meng. Discussion on the Application of Computer "Virtual Reality" Technology in Physical Education of Colleges and Universities [J]. Electronic Testing, 2013, (22):61-62.

[5] Bai Haijun, Gao Yunli. Research on the Application of Computer "Virtual Reality" Technology in Physical Education of Colleges and Universities [J]. Journal of Heilongjiang August First Land Reclamation University, 2013, (03):105-107+112.

[6] Zhang Tao. Exploration on the Application of Computer "Virtual Reality" Technology in Current Physical Education of Colleges and Universities [J]. Electronic Testing, 2013, (11):264-265. 